\title{
Therapeutic Effects of Resiniferatoxin Related with Immunological Responses for Intestinal Inflammation in Trichinellosis
}

\author{
José Luis Muñoz-Carrillo1,2,*, José Luis Muñoz-López ${ }^{3}$, José Jesús Muñoz-Escobedo4, Claudia Maldonado-Tapia1, \\ Oscar Gutiérrez-Coronado ${ }^{5}$, Juan Francisco Contreras-Cordero², María Alejandra Moreno-García ${ }^{1}$ \\ 'Laboratory of Cell Biology and Microbiology, Academic Unit of Biological Sciences, Autonomous University of Zacatecas, Zacatecas, Zacatecas, \\ México; 'Laboratory of Immunology and Virology, Faculty of Biological Sciences, Autonomous University of Nuevo Leon, San Nicolás de los Garza, \\ Nuevo León, México; ${ }^{3}$ Mexican Social Security Institute (IMSS), León, Guanajuato, México; ${ }^{4}$ Academic Unit of Odontology, Autonomous University \\ of Zacatecas, Guadalupe, Zacatecas, México; ${ }^{5}$ Laboratory of Immunology, Department of Earth and Life Sciences, University Center of Los Lagos, \\ University of Guadalajara, Lagos de Moreno, Jalisco, México
}

\begin{abstract}
The immune response against Trichinella spiralis at the intestinal level depends on the CD4 ${ }^{+} \mathrm{T}$ cells, which can both suppress or promote the inflammatory response through the synthesis of diverse cytokines. During the intestinal phase, the immune response is mixed (Th1/Th2) with the initial predominance of the Th1 response and the subsequent domination of Th2 response, which favor the development of intestinal pathology. In this context, the glucocorticoids (GC) are the pharmacotherapy for the intestinal inflammatory response in trichinellosis. However, its therapeutic use is limited, since studies have shown that treatment with GC suppresses the host immune system, favoring T. spiralis infection. In the search for novel pharmacological strategies that inhibit the Th1 immune response (proinflammatory) and assist the host against $T$. spiralis infection, recent studies showed that resiniferatoxin (RTX) had anti-inflammatory activity, which decreased the serum levels of IL-12, INF- $\gamma$, IL-1 $\beta$, TNF- $\alpha$, NO, and PGE 2 , as well the number of eosinophils in the blood, associated with decreased intestinal pathology and muscle parasite burden. These researches demonstrate that RTX is capable to inhibit the production of Th1 cytokines, contributing to the defense against $T$. spiralis infection, which places it as a new potential drug modulator of the immune response.
\end{abstract}

Key words: Trichinella spiralis, trichinellosis, inflammatory response, Th1 cytokine, resiniferatoxin

\section{INTRODUCTION}

Over 1 billion people are currently infected with gastrointestinal (GI) nematode parasites worldwide [1], making them one of the most prevalent infectious agents responsible for many diseases in both animals and humans [2], thus being a health problem worldwide [3]. The investigation of these parasitic infections is not only of direct relevance to human and animal health, but also because they present a constant and important challenge to the host immune system, especially through the intestinal tract [1], since both in humans and animals, nematodes establish chronic infections [4] associated

• Received 13 July 2017, revised 22 October 2017, accepted 12 November 2017

*Corresponding author (mcbjlmc@mail.com)

(c) 2017, Korean Society for Parasitology and Tropical Medicine

This is an Open Access article distributed under the terms of the Creative Commons Attribution Non-Commercial License (http://creativecommons.org/licenses/by-nc/4.0) which permits unrestricted non-commercial use, distribution, and reproduction in any

medium, provided the original work is properly cited. with a significant downregulation of the immune response $[5,6]$.

The first defense barrier during intestinal nematode-GI infection is the mucus layer secreted by the host's intestine, either in a larval stage during the early infectious process or as adult parasites during the reproductive phase of infection. Thus, nematodes-GI will interact with the mucus layer and in many cases, will have to cross it to reach the epithelial layer and thus thrive and reproduce within it [1].

The species of the nematode parasite of the genus Trichinella causes the disease called trichinellosis [7], which is a zoonotic parasitic disease [8] that is characterized by a wide range of hosts and geographic distribution [9]. Currently, 12 species are known, which in turn are composed of 2 main clades: the clade of the encapsulated species (T. spiralis, T. nativa, T. britovi, T. nelsoni, T. murrelli, and T. patagoniensis, T6, T8, and T9), as well as the clade of non-encapsulated species (T. pseudospiralis, T. papuae, and T. zimbabwensis) [10-12]. 


\section{LIFE CYCLE OF T. SPIRALIS}

The main feature of the epidemiology of T. spiralis is its obligatory transmission by ingestion of infected meat $[13,14]$. T. spiralis is a nematode parasite, which when it infects a host, its life cycle begins by the release of infective larvae of T. spiralis (T. spiralis-L1) in the stomach, which then invade the small intestine, where they mature to female and male adult worms (AD) to then produce newborn larvae (NBL) [15], giving rise to the intestinal phase of infection [16]. Subsequently, these NBL migrate mainly through the bloodstream invading the musculoskeletal cells to develop once again to a stage of T. spiralis- L1 forming the nurse cell (NC), giving rise to the muscular phase of the infection, and thus complete its life cycle (Fig. 1) [17,18].

\section{IMMUNE RESPONSES TO T. SPIRALIS INFECTION}

\section{Immunogenic antigens of $T$. spiralis}

T. spiralis infection represents a major challenge for the host immune system, as it is influenced by the antigenic compo- nents that occur in each stage of life of the parasite [19]. These antigens are of interest, since they elicit a protective immune response and are useful in the diagnosis of the trichinellosis in both humans and animals. These antigens have been named $T$. spiralis larvae group (TSL)-1, and they are released (secreted and/or excreted) by the T. spiralis-L1 in the intestinal epithelium, at the beginning of the intestinal phase, and again in the muscular phase of the infection when T. spiralis-L1 are in the muscle cells [20-22]. The antigens TSL-1 are glycoproteins 43, 53 , and $45 \mathrm{kDa}$ from excretory-secretory (E-S) products of $T$. spiralis-L1 [23], which are targets of antibodies that mediate the protective immunity against $T$. spiralis, which recognize their residues of tivelose $[22,24,25]$. Immunohistochemical techniques have detected TSL-1 antigens on the surface of T. spiralisL1, in a-stichocytes and E-S products [21]. TSL-1 antigens are released (secreted or excreted) by T. spiralis-L1 in the intestinal epithelium, and again when T. spiralis-L1 become residents of muscle cells, suggesting a functional role in parasitism [22].

Gold et al. [26] isolated the 43-kDa glycoprotein from E-S products of T. spiralis-L1. Subsequently, Su et al. [27], cloned and expressed this 43-kDa glycoprotein in Echerichia coli (E.

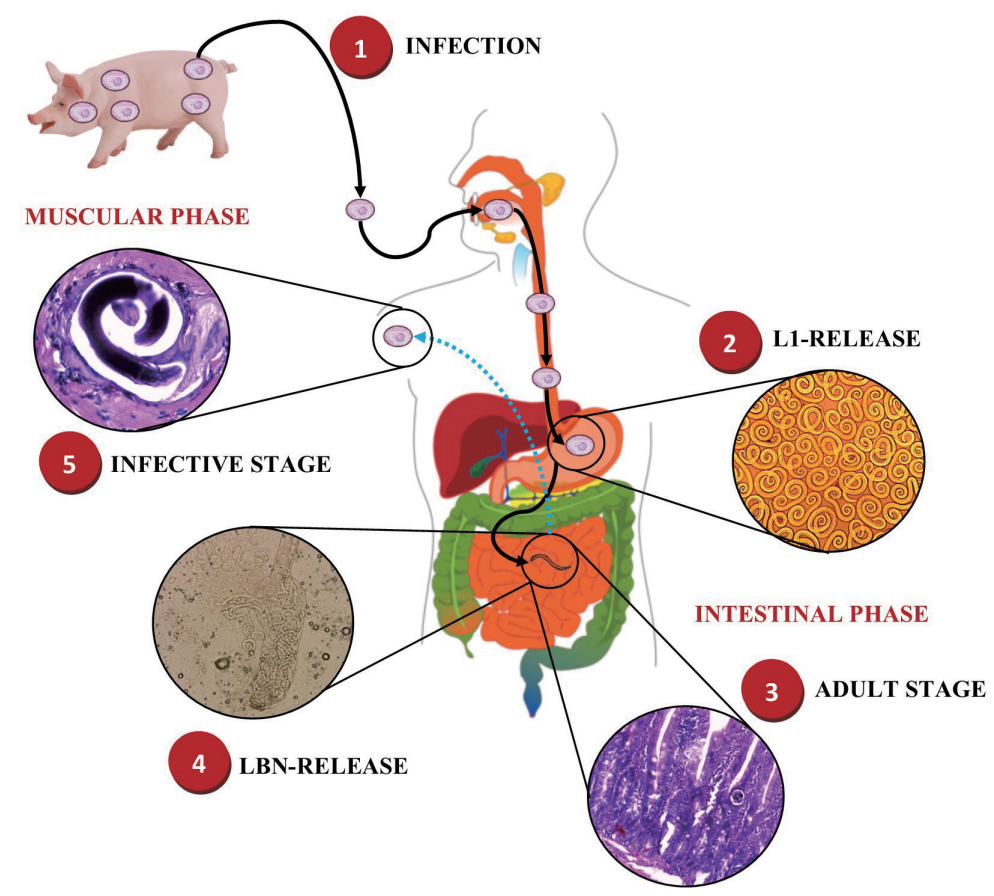

Fig. 1. Life cycle of Trichinella spiralis. 1) Infected meat ingestion with T. spiralis. Intestinal phase. 2) Release of infective larvae of T. spiralis (T. spiralis-L1) in the stomach. 3) Migration of T. spiralis-L1 to the small intestine and maturation to female and male adult worms (AD). 4) Reproduction and release of newborn larvae (NBL) of T. spiralis. Muscle phase. 5) Migration of NBL T. spiralis and invasion of skeletal muscle cells to develop to a stage of T. spiralis-L1 forming the nurse cell (NC). This figure was made by the authors based on the references cited in the text. 
coli). It's believed that the 43-kDa glycoprotein may be responsible for NC formation after the entry of NBL into muscle cells, since the gene that encodes this 43-kDa glycoprotein is expressed before and after NC formation, but not expressed by $\mathrm{AD}$ of T. spiralis [28]. In addition, it has been observed that various isoforms of the $43-\mathrm{kDa}$ gene have been expressed by immature T. spiralis-L1 [29]. Likewise, it was demonstrated that the mRNA production of the $43-\mathrm{kDa}$ antigen is limited to the muscle phase in T. spiralis-L1, within the a-stichocytes. It has also been detected in the nucleus and plasma of the $\mathrm{NC}$, which is the reason why it is believed that it is involved in the formation of NC [22,25].

Zarlenga and Gamle [30,31] identified the genes encoding the 53-kDa glycoprotein of T. spiralis, and subsequently elucidated the complete sequence and characterized the $53-\mathrm{kDa}$ gene. This gene encoding the $53-\mathrm{kDa}$ glycoprotein of T. spiralis is expressed by T. spiralis-L1 post-NC and AD T. spiralis, but not by pre-NC larva or by NBL [28]. This $53-\mathrm{kDa}$ glycoprotein is present in the $\beta$-granules but not in $\alpha$-granules of T. spiralis-L1, after formation of the NC [22,32]. In $\mathrm{AD}$ of T. spiralis, this 53$\mathrm{kDa}$ glycoprotein is present within the type I stichocyte granules. These data indicate that the 53-kDa glycoprotein is not responsible for muscle cell transformation or the NC formation, but it plays some role in the continuation of parasitism and modulation of host immune response [25].

Arasu et al. [33] revealed that the secreted $45-\mathrm{kDa}$ protein is a glycoprotein that contains tivelose and is present in the $\beta$ and $\alpha$-stichocytes of the secretory organs of T. spiralis-L1. The gene encoding this protein belongs to a family of genes present in a single DNA and encodes several proteins in the 40-50 $\mathrm{kDa}$ range. TSL- 1 antigens are involved in the acute inflammatory response during the intestinal phase of the infection, while later, in the muscle phase, they maintain a cross-relationship with the host [34].

\section{Intestinal immune responses in T. spiralis infection}

The onset of intestinal phase of T. spiralis infection is characterized by the induction of an early immune response of $\mathrm{T}$

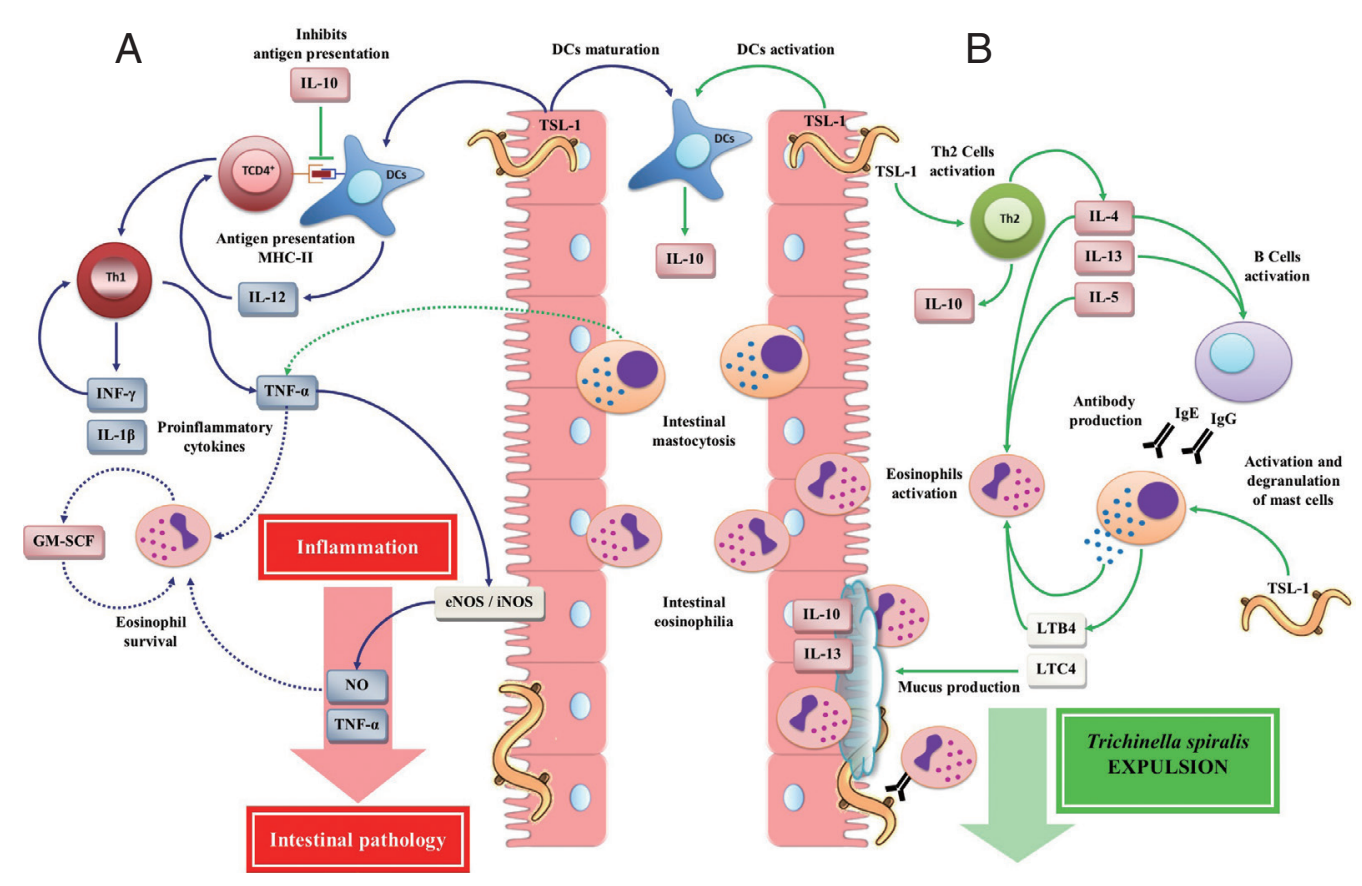

Fig. 2. Immune responses during the intestinal phase of $T$. spiralis infection. (A) T helper type 1 (Th1) immune response: $T$. spiralis larvae group antigens (TSL-1) induce maturation of dendritic cells (DCs) by polarizing a Th1 immune response, which is mainly characterized by the release of interleukin (IL)-12, interferon (INF)- $\gamma$, granulocyte macrophage colony-stimulating factor (GM-SCF), nitric oxide (NO), IL$1 \beta$, and tumor necrosis factor (TNF)- $a$, which together with eosinophilia (derived from the Th2 immune response) enhance intestinal inflammatory response, resulting in the development of intestinal pathology, creating a favorable environment for the T. spiralis survival. (B) T helper type 2 (Th2) immune response: TSL-1 antigens activate T cells that together with IL-10 induce a Th2 immune response characterized by the release of IL-4, IL-5, IL-10 and IL-13 favoring T. spiralis expulsion. This figure was made by the authors based on the references cited in the text. 
helper type 1 (Th1), with subsequent predominance of a Th2 type immune response, resulting in a mixture of both Th1/Th2 [35,36], immune responses dependents on $\mathrm{CD}^{+} \mathrm{T}$ cells [7]. These $\mathrm{CD} 4^{+} \mathrm{T}$ cells can function as antigen-presenting cells and play a key role in establishing the cytokine environment, thus directing their differentiation either by suppressing or favoring the inflammatory response at the intestinal level, which is crucial for the expulsion and elimination of the parasite [37].

\section{Th1 immune response; inflammatory responses}

During the intestinal phase of T. spiralis infection, the polarization of the cellular immune response to a Th1 type immune response depends on the type of signal derived from dendritic cells (DCs). DCs represent an important link between innate and adaptive immunity, which play an important role during the immune response against parasites [38,39]. TSL-1 antigens induce the DCs maturation, leading to the expression of histocompatibility complex (MHC) class II [40,41], promoting the development of a Th1 type cellular immune response (Fig. 2A) [19]. Several studies, both in vitro and in vivo, have shown that during the early stage of intestinal infection by T. spiralis there is a significant increase of Th1 cytokines such as interleukin (IL)12 [43,44], interferon (INF)- $\gamma[19,42-44]$, IL-1 $\beta$ [45] and tumor necrosis factor (TNF)- $\alpha[42,43]$.

IL-12 promotes the differentiation of naive T cells into INF$\gamma$-producing Th1 cells [46]. INF- $\gamma$ (type II interferon) is a cytokine that forms an important part of both innate and adaptive immunity, which is produced by various immune cells such as $\mathrm{CD}^{+} \mathrm{T}$ cells in response to some immune or inflammatory stimuli $[47,48]$, such as pathogens, specific antigens, or by activation of the T cell receptor. INF- $\gamma$ induces the expression of MHC class I and II molecules in DCs [49], enhances the development and differentiation of Th1 cells, induces the expression of inducible nitric oxide synthase (iNOS), activates transcription factors such as nuclear factor (NF)-kB [50] and regulates the production of pro-inflammatory cytokines such as TNF- $\alpha$ [51]. In the immune response against T. spiralis infection, IL-12 together with INF- $\gamma$, are of vital importance as they participate in the polarization of the Th1 type immune response [19,42-44]. However, the exogenous administration of IL-12 in T. spiralis infection suppresses intestinal mastocytosis, delaying the parasite expulsion and increasing the parasite burden at the muscle phase [52].

TNF- $\alpha$ is a potent pro-inflammatory cytokine produced by different types of immune system cells, such as DCs, macro- phages, Th1 cells, mast cells, etc., which participates in the activation of a cascade of pro-inflammatory cytokines, especially IL-1 $\beta$, IL-6, and IL-8 [53-55]. Studies have shown that TNF- $\alpha$ is a cytokine that is produced during the intestinal phase of $T$. spiralis infection [42,43]. However, several investigations have associated the production of TNF- $\alpha$ with the development of intestinal pathology during trichinellosis. One study showed that TNF receptor 1 (TNFR1)-deficient mice are still capable expelling T. spiralis, although a reduction in intestinal pathology was observed [56]. Another study showed that TNF- $\alpha$ derived from mast cells is necessary for mastocytosis, as well as for the generation of the Th2 immune response, which are both needed for the T. spiralis expulsion [57]. In addition, the TNF- $\alpha$ soluble form plays a critical role in the protection against $T$. spiralis through Th2 immune response, since the absence of soluble TNF- $\alpha$ in transgenic mice delayed the expulsion of T. spiralis, along with a reduction in intestinal pathology and mastocitosis [58].

One of the effects of TNF- $a$ is the iNOS expression and consequently the nitric oxide (NO) production [59-62], which acts mainly as an effector molecule against both extracellular and intracellular parasites [63]. In a study by Andrade et al. [64] it was observed that TSL-1 were capable to induce an increase in the iNOS expression, with consequent NO production. Also, Lawrence et al. [65] demonstrated that in iNOS knockout mice (C57BL/6) infected with 400 T. spiralis-L1, showed a reduction in the expression of Th2 cytokines (IL-4, IL-5), a reduced humoral response, (immunoglobulin, Ig, -G and -E), with a decrease in mastocytosis. However, no significant difference was observed in T. spiralis expulsion, although iNOS knockout mice showed a decrease in intestinal pathology compared to wild-type animals. These results suggest that NO is not required for T. spiralis expulsion, but its production is responsible for the intestinal pathology.

On the other hand, IL-1 $\beta$ is a pro-inflammatory and pyrogenic cytokine of excellence that regulates systemic and local responses through the generation of fever, activation of lymphocytes and promotion of recruitment and activation of myeloid cells at the site of infection. IL-1 $\beta$ has been shown to participate in host defense by inducing the adaptive immune response skewed to Th17 and Th1 cells [66,67]. In trichinellosis, the role of IL-1 $\beta$ is not well understood, however, it is known to participate in the intestinal inflammatory response, since T. spiralis-L1 is capable to increase levels of IL-1 1 derived from intestinal epithelial cells [45]. 
Recent research showed that during the intestinal phase of $T$. spiralis infection increased the synthesis of pro-inflammatory mediators such as prostaglandin (PG)- $\mathrm{E}_{2}$ and $\mathrm{NO}$, as well as the production of Th1 cytokines, such as, IL-12, INF- $\gamma$, IL-1 $\beta$ and TNF- $\alpha$, associated with increased eosinophils and the development of intestinal pathology $[68,69]$.

\section{Th2 immune response; T. spiralis expulsion}

The initial exposure of TSL- 1 antigens of T. spiralis activated $\mathrm{CD}^{+} \mathrm{T}$ cells [35], as well as DCs, leading to the secretion of large amounts of IL-10 [70]. IL-10 may suppress cell markers, the proliferation and antigen presentation by DCs and inhibition of IL-12 secretion. In addition, TSL-1 increased the both IL-4 and IL-10 production derived from Th2 cells with a decrease in INF- $\gamma$ production, polarizing the immune response to a strong Th2 cellular immune response (Fig. 2B), protective and responsible for the T. spiralis expulsion [35]. IL-10 is a Th2 cytokine, which is necessary for a successful intestinal immune response. This is because the absence or decrease of IL-10 causes a high susceptibility to the primary infection by $T$. spiralis, showing a significant delay in the T. spiralis expulsion and an increase in the parasite burden [71].

The Th2 immune response is also characterized by the synthesis and release of other cytokines such as IL-4, IL-5, and IL13, which stimulate IgE synthesis, inducing mast cell and eosinophil hyperplasia, triggering immediate hypersensitivity reactions, promoting the T. spiralis expulsion from the intestine [40,72-74]. Mast cells rapidly expand in the mucosa, predominantly within the epithelium [40], where TSL-1 antigens can directly induce their degranulation [24], releasing effector molecules such as histamine, serine proteases [40], TNF- $\alpha$ [74], which in combination with Th2 cytokines, such as IL-4 and IL13 , increase the contractility of smooth muscle cells, the permeability of epithelial cells and the production of mucus [43], generating changes in epithelial integrity of the small intestine [1], which contributes to the intestinal inflammation development $[24,75,76]$. Therefore, the activity of both IL-4 and IL-13 is required for: 1) the mast cells response, which leads to T. spiralis expulsion; and 2) the cytokines production, which control mast cell hyperplasia; since the IL-13 absence results in the inhibition of T. spiralis expulsion and the development of intestinal pathology [7]. Other mediators released by mast cell degranulation include leukotrienes, derived from acid arachidonic metabolism, which play an important role in the T. spiralis infection. Leukotriene (LT)-C4 causes smooth muscle contraction, increases vascular permeability and stimulates mucus hypersecretion. LT-B4 activates inflammatory cells such as eosinophils to promote T. spiralis expulsion. Thus, leukotrienes released from mast cells can effectively participate in the protective immune response against T. spiralis [74].

On the other hand, eosinophils are prominent inflammatory cells during inflammatory processes associated nematodeGI infection [77]. During T. spiralis infection, TSL-1 antigens stimulate Th2 cells, leading to cytokine release such as IL-4 and IL-5 [78], which are a critical factor in the terminal differentiation and proliferation of eosinophils, which are involved in tissue damage, thus promoting the inflammatory response $[79,80]$. It suggests that the protective role of the Th2 type immune response is not sufficient facing the challenge against $T$. spiralis, as it contributes to the development of immunopathology in trichinellosis.

\section{ANTI-INFLAMMATORY TREATMENT}

\section{Treatment of the inflammatory response in trichinellosis}

Pharmacotherapy used in trichinellosis includes: 1) the use of anti-parasitic drugs, such as benzimidazoles, mainly albendazole and mebendazole, which are directed against the parasite [80]; and 2) steroidal anti-inflammatory drugs, such as glucocorticoids (GC), whose purpose is to treat the signs and symptoms of the inflammatory response produced by the $T$. spiralis infection $[81,82]$.

\section{Glucocorticoids: steroidal anti-inflammatory drugs in trichinellosis}

Endogenous GC are steroid hormones synthesized and released from the adrenal cortex [83], which act to regulate transcriptional pathways in several cellular contexts such as development, homeostasis, metabolism, and inflammation [84]. While endogenous GC play a key role in many aspects of both health and disease, exogenous synthetic GC have been extensively used therapeutically as anti-inflammatory drugs $[85,86]$.

At the cellular level, the action of the GC is mediated by the GC receptor (GR), which is associated with various heat shock proteins (HSPs) 90, 70, and p23, as well as other proteins that keep it in an inactive conformation [87]. The binding of GR to the GC causes its dissociation and consequent translocation from cytoplasm to cell nucleus $[88,89]$. Once in the nucleus the GC-GR complex binds as a homodimer to specific DNA sequences (glucocorticoid response element, GRE) in the pro- 


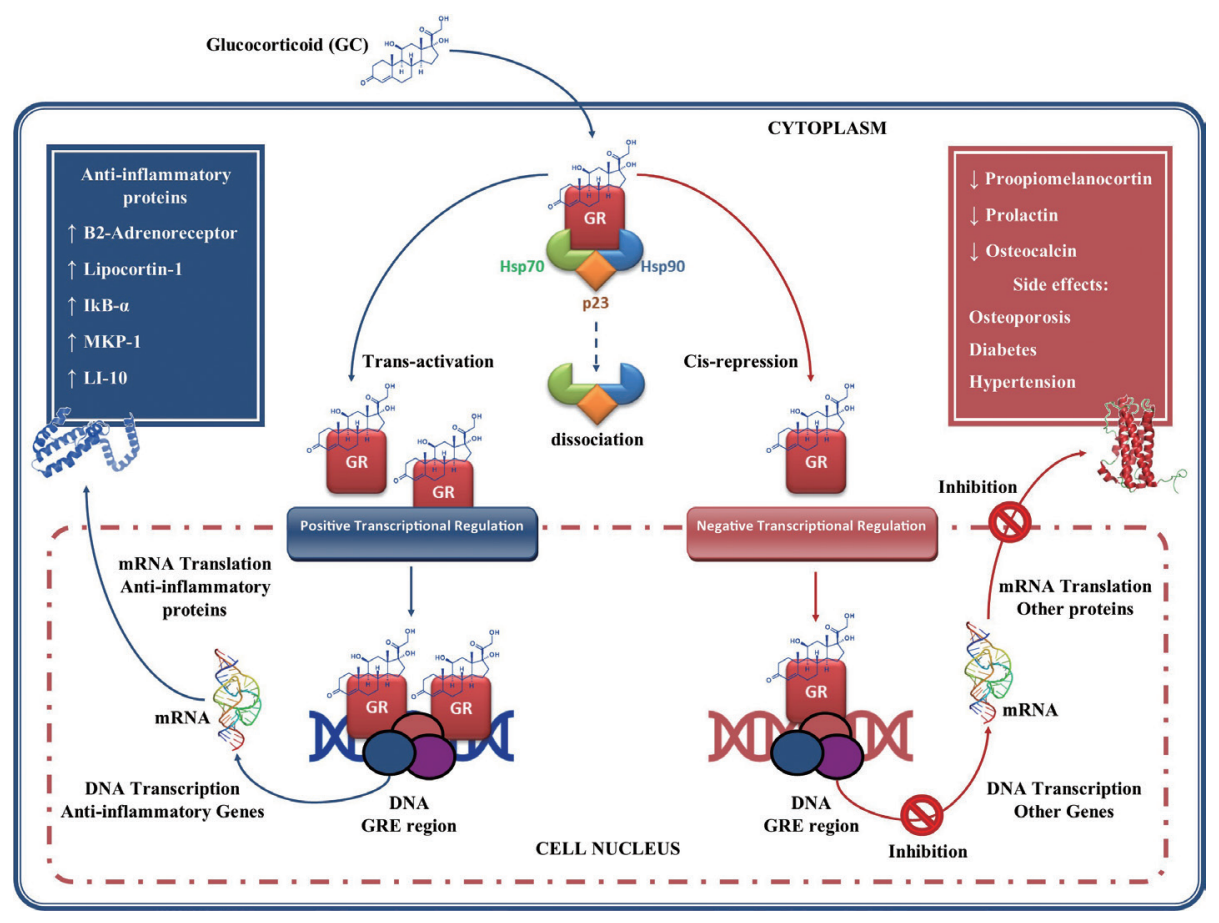

Fig. 3. Glucocorticoids gene regulation. Glucocorticoids (GC) enter the cell to bind the GC receptor (GR) in the cytoplasm forming a complex GC-GR which is then translocated to the cell nucleus. Once in the nucleus they bind to glucocorticoid response element (GRE), thus regulating gene expression in 2 ways: 1) through transactivation of genes that encodes anti-inflammatory proteins; and 2) through cis-repression of genes associated with their side effects. This figure was made by the authors based on the references cited in the text.

moter regions of glucocorticoid-regulated genes, regulating their expression positively or negatively (Fig. 3) [87]. In the transcriptional regulation positive or trans-activation, genes are activated that encoding $\beta 2$-adrenergic receptors, lipocortin-1, inhibitory secretory protein (IKB- $\alpha$ ), mitogen-activated kinase phosphatase-1 (MKP-1, which inhibits MAP kinase pathways), anti-inflammatory cytokines such as IL-10, and the IL-1. These effects may contribute to the anti-inflammatory actions of GC $[90,91]$. In negative transcriptional regulation or cis-repression, GC can suppress genes transcription such as pro-opiomelanocortin, hormone adrenocorticotropic (ACTH) precursor, prolactin, Osteocalcin involved in bone synthesis, which leads to the GC side effects such as osteoporosis, diabetes and hypertension $[88,90,92]$.

On the other hand, GC also act as immunosuppressants, since they regulate the function of several inflammatory cells [93]. In addition, GC inhibit the expression of proinflammatory genes by transcription factors suppression, such as NF- $\mathrm{kB}$ [94-96] and the activator protein (AP)-1 through a proteinprotein [97], by regulating the expression of genes encoding many inflammatory cytokines, such as TNF- $\alpha$, IL- $1 \alpha$, IL-1 $\beta$, IL8 , IFN- $\alpha$, and IFN- $\beta$, inflammatory enzymes such as iNOS, cy- clooxygenase (COX)-2, inducible phospholipase (CPL)-A2, adhesion molecules and inflammatory receptors (Fig. 4) [98,99]. Another mechanism of action by GC is through the inhibition of signaling in the pathways of mitogen-activated protein kinase (MAP kinase or MAPK), which are activated by inflammatory stimuli, such as IL-1, TNF- $\alpha$, microbial products such as lipopolysaccharide (LPS) and cell stress, such as ultraviolet (UV) radiation [89]. Once activated, MAPK phosphorylate various substrates, including other proteins that control gene expression and other processes. For example, MAPK activate NF- $k B$, through phosphorylation of their inhibitor IкB, and AP-1. In this mechanism, the GC inhibit the signaling pathways of the MAPK exerting their anti-inflammatory effect. This suggests that GC may block the signaling of the inflammatory response at a level above the transcription factors activation (Fig. 4) [100].

Recent research showed that dexamethasone (DEX) treatment during the intestinal phase of $T$. spiralis infection inhibited the production of pro-inflammatory mediators, such as $\mathrm{PGE}_{2}, \mathrm{NO}$, IL-12, INF- $\gamma$, IL-1 $\beta$, and TNF- $\alpha$; the number of eosinophils in the blood and intestinal pathology decreased, with a reduction in the hyperplasia of the intestinal crypt and the reconsti- 


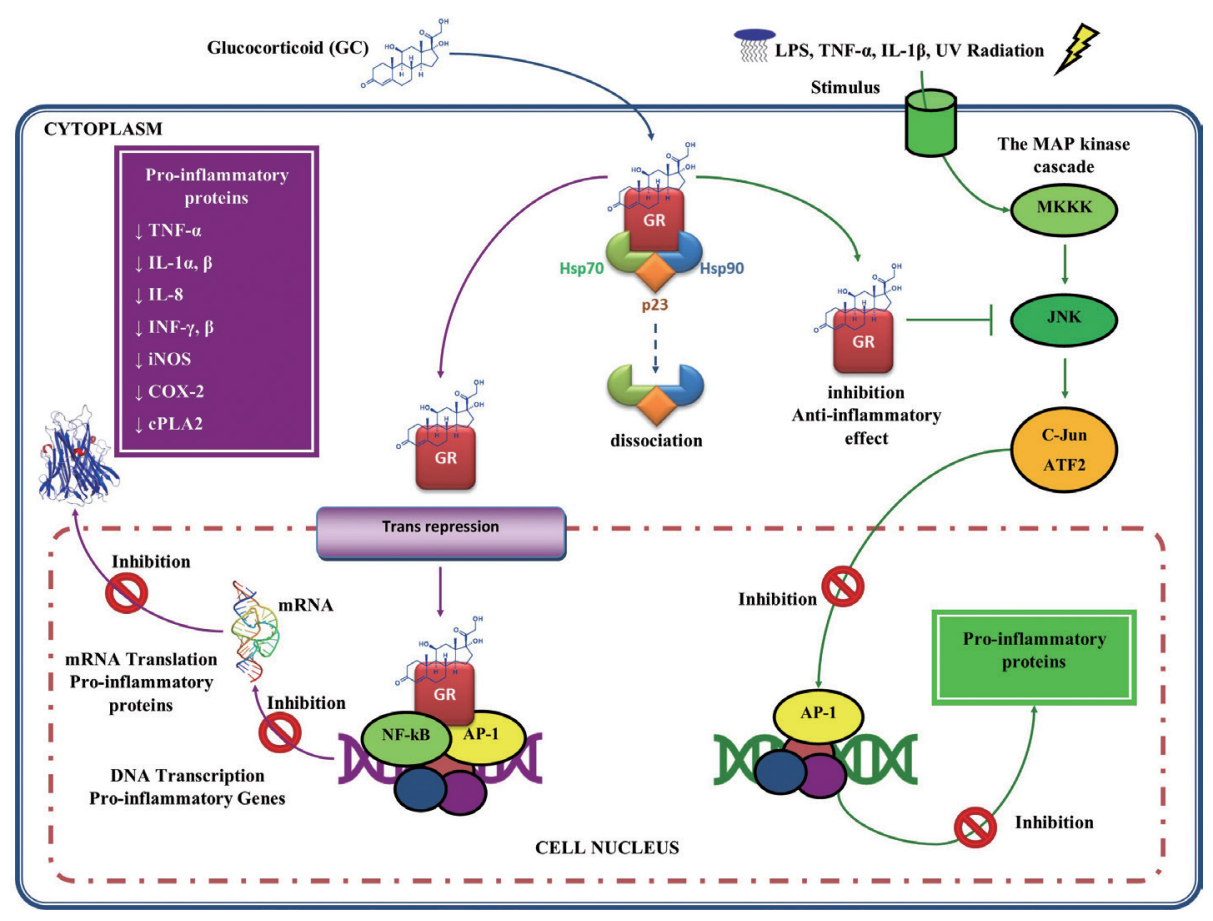

Fig. 4. Glucocorticoids anti-inflammatory activity. The complex GC-GR can also interact with proinflammatory transcription factors such as nuclear factor (NF)-кB and activator protein (AP)-1, repressing them and thus inhibiting proinflammatory gene expression. GC may also act by inhibiting mitogen-activated protein (MAP) kinases, blocking the mechanisms of transcription and translation, underlying the expression of inflammatory genes. This figure was made by the authors based on the references cited in the text.

tution of the intestinal villus $[68,69]$. This suppression of proinflammatory mediators by DEX is due to its aforementioned genomic effects. With respect to it activity on eosinophils, it has been shown that DEX inhibits the eosinophils survival in a dose-dependent manner [101], inducing apoptosis through increased activity of caspases 2, 3, 6, and 8 [102].

Although GC are potent anti-inflammatory drugs, their therapeutic use in trichinellosis is limited, since previous studies have shown that GC treatment suppresses the host immune system, favoring T. spiralis infection [103]. A study showed that in rats treated with betamethasone were more susceptible to T. spiralis infection, as an increase in parasite burden was observed compared to the infected control group [104]. Another study showed similar results, where it was observed that treatment with DEX increased the proportion of apoptotic and necrotic lymphocytes, as well as the number of T. spiralis-L1 in muscle tissue in mice [105]. Recent research from our research group showed that treatment with DEX in the intestinal phase of T. spiralis infection significantly increased T. spiralis-L1 implantation in muscle tissue as well as parasite burden $[68,69]$. This is due to the systemic suppression of the immune response by DEX.

\section{Resiniferatoxin: a novel anti-inflammatory treatment in trichinellosis}

Due to the limited pharmacological efficacy of GC against $T$. spiralis infection, the need arises to investigate new pharmacological strategies based on the suppression of the Th1 type immune response, which will help the host against $T$. spiralis infection. A molecule with therapeutic potential for suppression of the Th1 response during T. spiralis infection could be resiniferatoxin (RTX). RTX is a vanilloid derived from a cactus-like plant named Euphoria resiniferous, an agonist of the transient receptor potential vanilloid 1 (TRPV1) [106-108], which activates and then desensitizes the TRPV1 receptor, producing analgesia $[109,110]$. Besides to the multiple biological actions of the RTX mediated through TRPV1, studies have shown that RTX has an important anti-inflammatory activity in both in vitro and in vivo models. One study showed that RTX inhibited the expression of NF-kB in a dose-dependent manner in human myelomonoblastic leukemia cell (ML-1a) line stimulated with TNF- $\alpha$ (Fig. 5A) [111]. Similarly, another study showed that RTX inhibited the expression of iNOS and COX-2 in macrophages RAW264.7 stimulated with LPS and IFN- $\gamma$, resulting in a decrease in $\mathrm{PGE}_{2}$ and $\mathrm{NO}$ (Fig. 5B) [112]. 
A

A) ML-1a cell

B B) Macrophages RAW264.7

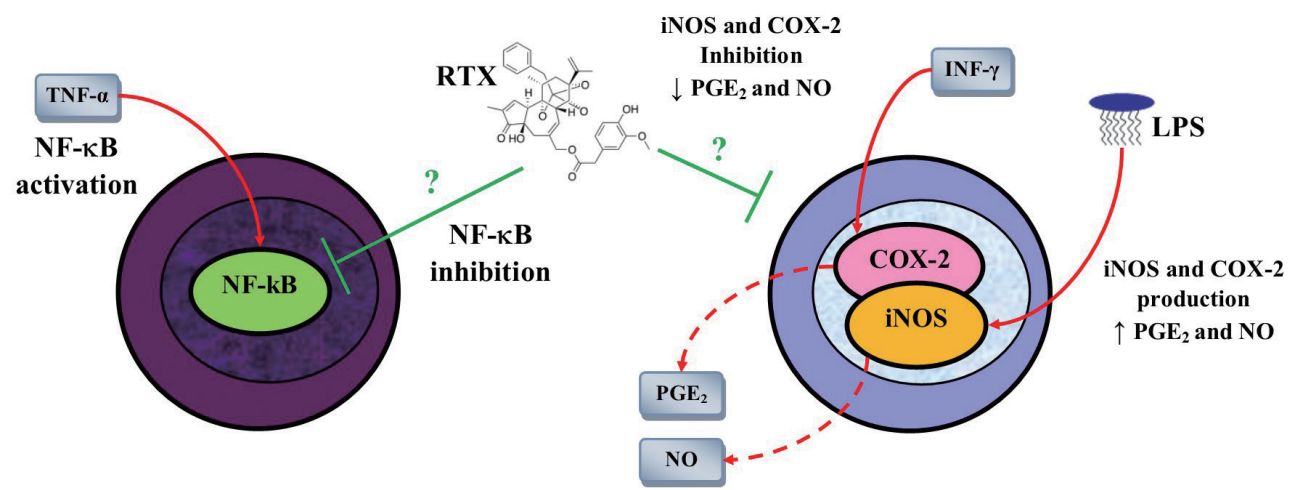

Fig. 5. Anti-inflammatory activity of resiniferatoxin on in vitro models. (A) Resiniferatoxin (RTX) inhibits the expression of nuclear factor (NF)$\kappa \mathrm{B}$ in a dose-dependent manner in human myelomonoblastic leukemia (ML-1a) cells previously stimulated with tumor necrosis factor (TNF)-a. (B) RTX inhibits the expression of nitric oxide synthase (iNOS) and cyclooxygenase (COX)-2 in macrophages RAW264.7 stimulated with lipopolysaccharide (LPS) and interferon (INF)- $\gamma$. This figure was made by the authors based on the references cited in the text.
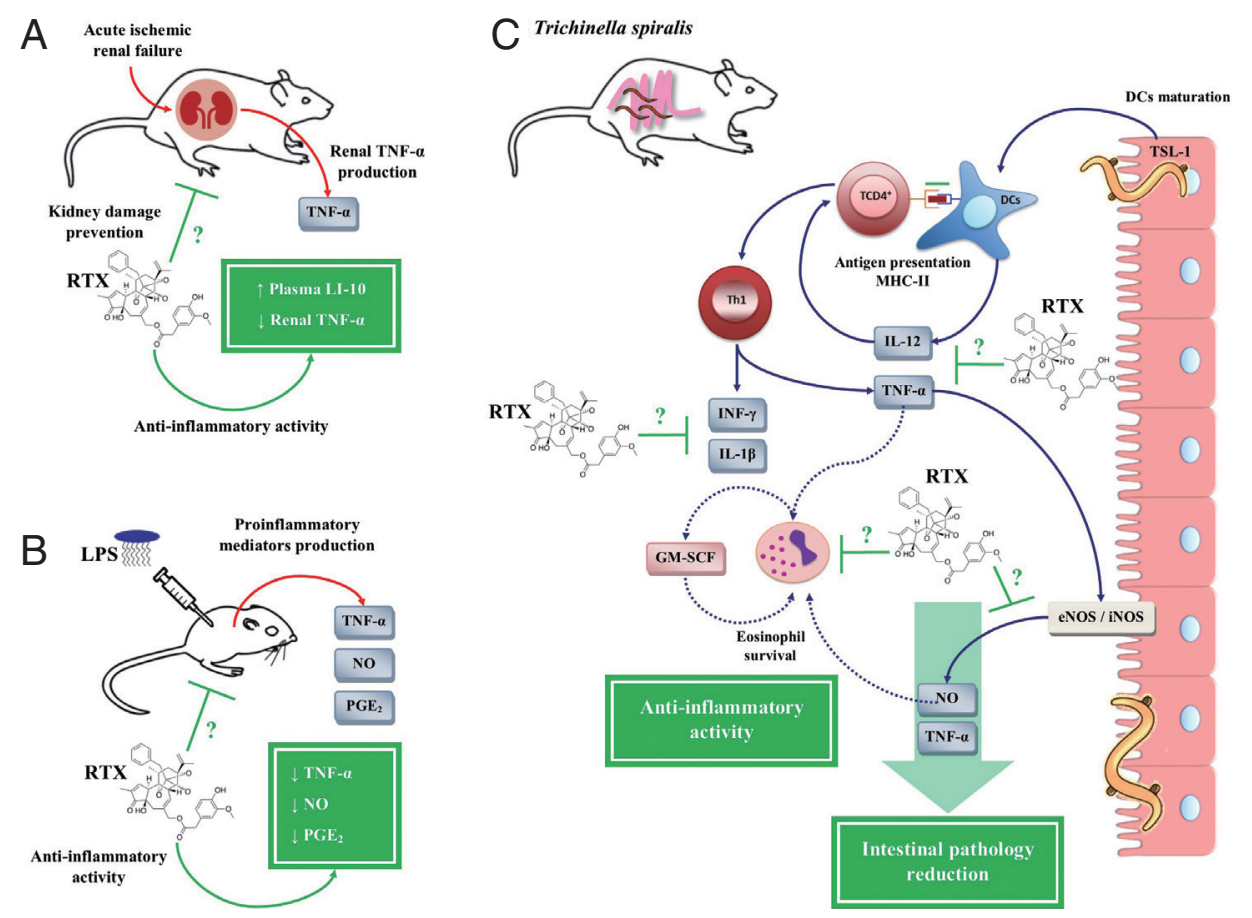

Fig. 6. Anti-inflammatory activity of resiniferatoxin on in vivo models. (A) Decrease of renal tumor necrosis factor (TNF)-a with an increase of plasma interleukin (IL)-10 in an acute ischemic renal failure (ARF) model in rats treated with resiniferatoxin (RTX). (B) Decreased serum levels of prostaglandin (PG)- $E_{2}$, nitric oxide (NO), and TNF-a in a BALB/c mice model stimulated with lipopolysaccharide (LPS), treated with RTX. (C) Inhibition of pro-inflammatory mediators, such as IL-12, interferon (IFN)- $\gamma, N O, P G E_{2}$, IL-1 $\beta$, and TNF- $a$, during the intestinal phase of T. spiralis infection, treated with RTX. This figure was made by the authors based on the references cited in the text.

On the other hand, a study based on a model of acute ischemic renal failure (ARF) in rats showed that RTX treatment prevented renal damage by inhibiting the inflammatory response, simultaneously decreasing the expression of renal TNF- $\alpha$ and an increase in IL-10 in plasma (Fig. 6A) [113]. An- other study in LPS-stimulated BALB/c mice showed that RTX significantly decreased serum levels of $\mathrm{PGE}_{2}, \mathrm{NO}$ and TNF- $\alpha$ (Fig. 6B) [114]. Based on these studies, our research group evaluated the therapeutic potential of RTX for the treatment of the inflammatory response during the intestinal phase of $T$. 
spiralis infection. On the one hand, the treatment with RTX showed anti-inflammatory activity, since it decreased the serum levels of PGE 2 , NO, IL-12, INF- $\gamma$, IL-1 $\beta$, and TNF- $\alpha$ in rat model, showing an immunomodulatory effect by RTX on the Th1 immune response. On the other hand, treatment with RTX showed a protective effect against $T$. spiralis infection, both in the intestinal phase and in the muscle phase. During the intestinal phase, apart from downregulation of the Th1 immune response, treatment with RTX decreased the number of eosinophils in the blood. While in the muscle phase of T. spiralis infection, treatment with RTX significantly decreased T. spiralisL1 implantation in the muscle tissue, as well as a reduction in parasite burden (Fig. 6C) [68,69].

These investigations are the first to show the protective effect of RTX against T. spiralis infection. Currently, there is no scientific evidence of how RTX could be affecting the survival of eosinophils, as well as the life cycle of T. spiralis. Our hypothesis, on one hand, is that perhaps the decrease in the number of eosinophils in the blood might be associated with the anti-inflammatory activity of RTX. This is because several studies have associated eosinophil survival with TNF- $\alpha$ production, since TNF- $\alpha$ derived from mast cells induces eosinophil survival by autocrine production of granulocyte-macrophage colony-stimulating factor (GM-CSF) [115] and, in addition, TNF- $\alpha$ is involved in the eosinophils adhesion to endothelial cells and induces activation, degranulation and production of eosinophil cytokines [116]. Furthermore, previous studies have also related eosinophil survival with the production of $\mathrm{NO}$, since $\mathrm{NO}$ is associated with apoptosis, which is important in promoting the removal of granulocytes in the inflammatory response. Peripheral eosinophil apoptosis is mediated by the binding of the CD95 death receptor to its CD95L ligand (Fas/APO-1), which leads to activation of caspase and a programmed cell death $[117,118]$. The role of the CD95/CD95L axis in eosinophils is mediated by NO, which interferes with the CD95 receptor in the signaling cascade and blocks the death signal in peripheral eosinophils [119]. On the other hand, the reduction of parasite burden may be associated with a decrease in the number of eosinophils, both as a result of RTX treatment. This is because, studies have shown that the absence of eosinophils decreases the parasite burden in the muscle phase of $\mathrm{T}$ spiralis infection [120] and that eosinophils may influence the immune response in a way that sustains chronic infection and ensures T. spiralis survival in the host [121-123].

\section{CONCLUSIONS}

T. spiralis, through the production of its antigens, has the capacity to induce a Th1 type immune response, responsible for the inflammatory response produced during the intestinal phase of the infection. Subsequently, T. spiralis is capable to polarize this immune response to a Th2 type immune response, which is believed to protect the host through the elimination of T. spiralis. However, both responses are involved in the development of intestinal pathology, which favors parasitism in the host. In this context, the pharmacological treatment to treat the inflammatory response during trichinellosis is through the use of steroidal anti-inflammatory drugs such as GC. However, based on the low pharmacological efficacy of GC against T. spiralis infection, the need arises to investigate molecules with therapeutic potential such as RTX. RTX has shown a potent anti-inflammatory activity against $T$. spiralis infection, because in addition to down-regulating Th1 cytokine expression, it reduces eosinophilia and intestinal pathology. Therefore, future research is needed to help understand the underlying mechanisms of RTX on the inflammatory response, which will allow us to evaluate its therapeutic use, placing it as a potential anti-inflammatory drug for the treatment of inflammatory disease.

\section{ACKNOWLEDGMENTS}

We thank the Academic Unit of Biological Sciences of the Autonomous University of Zacatecas, the Faculty of Biological Sciences, Autonomous University of Nuevo Leon and CONACyT for the financial support. This article is dedicated to Dr. J. L. Muñoz-López, thanks for your support and collaboration. J. L. Muñoz-López passed away before the submission of the final version of this manuscript. J. L. Muñoz-Carrillo accepts responsibility for the integrity and validity of the data collected and analyzed.

\section{CONFLICT OF INTEREST}

We have no conflict of interest related to this work.

\section{REFERENCES}

1. Grencis RK, Humphreys NE, Bancroft AJ. Immunity to gastrointestinal nematodes: mechanisms and myths. Immunol Rev 
2014; 260: 183-205.

2. McSorley HJ, Maizels RM. Helminth infections and host immune regulation. Clin Microbiol Rev 2012; 25: 585-608.

3. Maizels RM, Hewitson JP, Smith KA. Susceptibility and immunity to helminth parasites. Curr Opin Immunol 2012: 24: 459466.

4. Zaph C, Cooper PJ, Harris NL. Mucosal immune responses following intestinal nematode infection. Parasite Immunol 2014; 36: 439-452.

5. Elliott DE, Summers RW, Weinstock JV. Helminths as governors of immune-mediated inflammation. Int J Parasitol 2007; 37: 457-464.

6. Maizels RM, Yazdanbakhsh M. Immune regulation by helminth parasites: cellular and molecular mechanisms. Nat Rev Immunol 2003; 3: 733-744.

7. Bruschi F, Chiumiento L. Immunomodulation in trichinellosis: does Trichinella really ecape the host immune system? Endocr Metab Immune Disord Drug Targets 2012; 12: 4-15.

8. Laverde LM, Builes LM, Masso CJ. Detección de Trichinella spiralis en cerdos faenados en dos plantas de beneficio en el municipio de bello. Revista CES. Medicina Veterinaria y Zootecnia 2009; 4: 47-56.

9. Bruschi F. Trichinellosis in developing countries: is it neglected? J Infect Dev Ctries 2012; 6: 216-222.

10. Pozio E. World distribution of Trichinella spp. infections in animals and humans. Vet Parasitol 2007; 149: 3-21.

11. Krivokapich SJ, Pozio E, Gatti GM, Prous CL, Ribicich M, Marucci G, La Rosa G, Confalonieri V. Trichinella patagoniensis n. sp. (Nematoda), a new encapsulated species infecting carnivorous mammals in South America. Int J Parasitol 2012; 42: 903-910.

12. Pozio E, Zarlenga DS. New pieces of the Trichinella puzzle. Int J Parasitol 2013; 43: 983-997.

13. Bruschi F, Murrell KD. New aspects of human trichinellosis: the impact of new Trichinella species. Postgrad Med J 2002; 78: 1522.

14. Murrell KD. The dynamics of Trichinella spiralis epidemiology: out to pasture? Vet Parasitol 2016; 231: 92-96.

15. Theodoropoulos G, Petrakos G. Trichinella spiralis: differential effect of host bile on the in vitro invasion of infective larvae into epithelial cells. Exp Parasitol 2010; 126: 441-444.

16. Moreno García MA, Maldonado Tapia CH, García Mayorga EA, Reveles Hernández RG, Muñoz Escobedo JJ. Fase Intestinal de Trichinella spiralis en modelo murino. Acta biol Colomb 2009; 14: 203-210 (in Spanish).

17. Moreno AG, Maldonado CT, Chávez Ruvalcaba IR, Reveles RGH, Núñez QZ, Muñoz JJE. El estudio de Trichinella spiralis en modelos experimentales. REDVET 2012; 13: 1-12.

18. Wu Z, Sofronic-Milosavljevic L, Nagano I, Takahashi Y. Trichinella spiralis: nurse cell formation with emphasis on analogy to muscle cell repair. Parasit Vectors 2008; 1: 1-27.

19. Gruden-Movsesijan A, Ilic N, Colic M, Majstorovic I, Vasilev S, Radovic I, Sofronic-Milosavljevic LJ. The impact of Trichinella spiralis excretory-secretory products on dendritic cells. Comp
Immunol Microbiol Infect Dis 2011; 34: 429-439.

20. Ortega-Pierres MG, Yepez-Mulia L, Homan W, Gamble HR, Lim PL, Takahashi Y, Wassom DI, Appleton JA. Workshop on a detailed characterization of Trichinella spiralis antigens: a platform for future studies on antigens and antibodies to this parasite. Parasite Immunol 1996; 6: 273-284.

21. Appleton JA, Romaris F. A pivotal role for glycans at the interface between Trichinella spiralis and its host. Vet Parasitol 2001; 101: 249-260.

22. Yépez-Mulia L, Hernández-Bello R, Arizmendi-Puga N, OrtegaPierres G. Contributions to the study of Trichinella spiralis TSL-1 antigens in host immunity. Parasite Immunol 2007; 29: 661670.

23. Bolás-Fernandez F, Corral Bezara LD. TSL-1 antigens of Trichinella: an overview of their potential role in parasite invasion, survival and serodiagnosis of trichinellosis. Res Vet Sci 2006; 81: 297-303.

24. Reason AJ, Ellis LA, Appleton JA, Wisnewski N, Grieve RB, McNeil M, Wassom DL, Morris HR, Dell A. Novel tyvelose-containing tri- and tetra-antennary N-glycans in the immunodominant antigens of the intracellular parasite Trichinella spiralis. Glycobiology 1994; 5: 593-603.

25. Nagano I, Wu Z, Takahashi Y. Functional genes and proteins of Trichinella spp. Parasitol Res 2009; 104: 197-207.

26. Gold AM, Despommier DD, Buck SW. Partial characterization of two antigens secreted by L1 larvae of Trichinella spiralis. Mol Biochem Parasitol 1990; 41: 187-196.

27. Su XZ, Prestwood AK, McGraw RA. Cloning and expression of complementary DNA encoding an antigen of Trichinella spiralis. Mol Biochem Parasitol 1991; 45: 331-336.

28. Wu Z, Nagano I, Nakada T, Takahashi Y. Expression of excretory and secretory protein genes of Trichinella at muscle stage differs before and after cyst formation. Parasitol Int 2002; 51: 155161.

29. Mitreva M, Jasmer DP, Appleton J, Martin J, Dante M, Wylie T, Clifton SW, Waterston RH, McCarter JP. Gene discovery in the adenophorean nematode Trichinella spiralis: an analysis of transcription from three life cycle stages. Mol Biochem Parasitol 2004; 137: 277-291.

30. Zarlenga DS, Gamble HR. Molecular cloning and expression of an immunodominant 53-kDa excretory-secretory antigen from Trichinella spiralis muscle larvae. Mol Biochem Parasitol 1990; 42: 165-174.

31. Zarlenga DS, Gamble HR. Molecular cloning and expression of an immunodominant 53-kDa excretory-secretory antigen from Trichinella spiralis muscle larvae. Mol Biochem Parasitol 1995; 72: 253.

32. Romarís F, Escalante M, Lorenzo S, Bonay P, Gárate T, Leiro J, Ubeira FM. Monoclonal antibodies raised in Btk (xid) mice reveal new antigenic relationships and molecular interactions among gp53 and other Trichinella glycoproteins. Mol Biochem Parasitol 2002; 125: 173-183.

33. Arasu P, Ellis LA, Iglesias R, Ubeira FM, Appleton JA. Molecular 
analysis of antigens targeted by protective antibodies in rapid expulsion of Trichinella spiralis. Mol Biochem Parasitol 1994; 65: 201-211.

34. Beiting DP, Gagliardo LF, Hesse M, Bliss SK, Meskill D, Appleton JA. Coordinated control of immunity to muscle stage Trichinella spiralis by IL-10, regulatory T Cells, and TGF-b. J Immunol 2007; 178: 1039-1047.

35. Ilic N, Gruden-Movsesijan A, Sofronic-Milosavljevic L. Trichinella spiralis: shaping the immune response. Immunol Res 2012; 52: 111-119.

36. Ashour DS. Trichinella spiralis immunomodulation: an interactive multifactorial process. Expert Rev Clin Immunol 2013; 7: 669-675.

37. Cieza RJ, Cao AT, Cong Y, Torres AG. Immunomodulation for gastrointestinal infections. Expert Rev Anti Infect Ther 2012; 3: 391-400.

38. Koenderman L, Buurman W, Daha MR. The innate immune response. Immunol Lett 2014; 162: 95-102.

39. Sher A, Pearce E, Kaye P. Shaping the immune response to parasites: role of dendritic cells. Curr Opin Immunol 2003; 4: 421429.

40. Ilic N, Worthington JJ, Gruden-Movsesijan A, Travis MA, Sofronic-Milosavljevic L, Grencis RK. Trichinella spiralis antigens prime mixed Th1/Th2 response but do not induce de novo generation of Foxp3? T cells in vitro. Parasite Immunol 2011; 33: 572-582.

41. Sofronic-Milosavljevic L, Ilic N, Pinelli E, Gruden-Movsesijan A. Secretory products of Trichinella spiralis muscle larvae and immunomodulation: implication for autoimmune diseases, allergies, and malignancies. J Immunol Res 2015; 31: 523875.

42. Yu YR, Deng MJ, Lu WW, Jia MZ, Wu W, Qi YF. Systemic cytokine profiles and splenic toll-like receptor expression during Trichinella spiralis infection. Exp Parasitol 2013; 134: 92-101.

43. Gentilini MV, Nuñez GG, Roux ME, Venturiello SM. Trichinella spiralis infection rapidly induces lung inflammatory response: the lung as the site of helminthocytotoxic activity. Immunobiology 2011; 216: 1054-1063.

44. Ilic N, Colic M, Gruden-Movsesijan A, Majstorovic I, Vasilev S, Sofronic-Milosavljevic LJ. Characterization of rat bone marrow dendritic cells initially primed by Trichinella spiralis antigens. Parasite Immunol 2008; 30: 491.

45. Ming L, Peng RY, Zhang L, Zhang CL, Lv P, Wang ZQ, Cui J, Ren HJ. Invasion by Trichinella spiralis infective larvae affects the levels of inflammatory cytokines in intestinal epithelial cells in vitro. Exp Parasitol 2016; 170: 220-226.

46. Teng MW, Bowman EP, McElwee JJ, Smyth MJ, Casanova JL, Cooper AM, Cua DJ. IL-12 and IL-23 cytokines: from discovery to targeted therapies for immune-mediated inflammatory diseases. Nat Med 2015; 21: 719-729.

47. BarbuleacuK B. IL-12 and IL-18 differentially regulate the transcriptional activity of the human IFN- $\gamma$ promoter in primary CD4 ${ }^{+}$T lymphocytes. J Immunol 1998; 160: 3642-3647.

48. Bogdan C, Schleicher U. Production of interferon- $\gamma$ by myeloid cells-fact or fancy? Trends Immunol 2006; 27: 282-290.

49. Pestka S, Krause CD, Walter MR. Interferons, interferon-like cytokines, and their receptors. Immunol Rev 2004; 202: 8-32.

50. Mühl H, Pfeilschifter J. Anti-inflammatory properties of pro-inflammatory interferon- $\gamma$. Int Immunopharmacol 2003; 3(9): 1247-1255.

51. Neumann B, Emmanuilidis K, Stadler M, Holzmann B. Distinct functions of interferon-gamma for chemokine expression in models of acute lung inflammation. Immunology 1998; 95: 512-521.

52. Helmby $\mathrm{H}$, Grencis RK. IFN- $\gamma$-independent effects of IL-12 during intestinal nematode infection. J Immunol 2003; 171: 3691-3696.

53. Leung L, Cahill CM. TNF- $\alpha$ and neuropathic pain-a review. J Neuroinflammation 2010; 7: 27.

54. Horiuchi T, Mitoma H, Harashima SI. Transmembrane TNF- $\alpha$ : structure, function and interaction with anti-TNF agents. Rheumatology (Oxford) 2010; 49: 1215-1228.

55. Parameswaran N, Patial S. Tumor necrosis factor- $\alpha$ signaling in macrophages. Crit Rev Eukaryot Gene Expr 2010; 20: 87-103.

56. Lawrence CE, Paterson JC, Higgins LM, MacDonald TT, Kennedy MW, Garside P. IL-4-regulated enteropathy in an intestinal nematode infection. Eur J Immunol 1998; 28: 2672-2684.

57. Ierna MX, Scales HE, Saunders KL, Lawrence CE. Mast cell production of IL- 4 and TNF may be required for protective and pathological responses in gastrointestinal helminth infection. Mucosal Immunol 2008; 1: 147-155.

58. Ierna MX, Scales HE, Müller C, Lawrence CE. Transmembrane tumor necrosis factor alpha is required for enteropathy and is sufficient to promote parasite expulsion in gastrointestinal helminth infection. Infect Immun 2009; 77: 3879-3885.

59. Bogdan C. Nitric oxide and the immune response. Nat Immunol 2001; 2: 907-916.

60. Guzik TJ, Korbut R, Adamek-Guzik T. Nitric oxide and superoxide in inflammation and immune regulation. J Physiol Pharmacol 2003; 54: 469-487.

61. Marzocco S, Di Paola R, Serraino I, Sorrentino R, Meli R, Mattaceraso G, Cuzzocrea S, Pinto A, Autore G. Effect of methylguanidine in carrageenan-induced acute inflammation in the rats. Eur J Pharmacol 2004; 484: 341-350.

62. Wink DA, Hines HB, Cheng RYS, Switzer CH, Flores-Santana W, Vitek MP, Ridnour LA, Colton CA. Nitric oxide and redox mechanisms in the immune response. J Leukoc Biol 2011; 89: 873-891.

63. Moncada S, Erusalimsky JD. Does nitric oxide modulate mitochondrial energy generation and apoptosis? Nat Rev Mol Cell Biol 2002; 3: 214-220.

64. Andrade MA, Siles-Lucas M, López-Abán J, Nogal-Ruiz JJ, Pérez-Arellano JL, Martínez-Fernández AR, Muro A. Trichinella: differing effects of antigens from encapsulated and non-encapsulated species on in vitro nitric oxide production. Vet Parasitol 2007; 143: 86-90.

65. Lawrence CE, Paterson JC, Wei XQ, Liew FY, Garside P, Kenne- 
dy MW. Nitric oxide mediates intestinal pathology but not immune expulsion during Trichinella spiralis infection in mice. J Immunol 2000; 164: 4229-4234.

66. Dinarello CA. Immunological and inflammatory functions of the interleukin-1 family. Annu Rev Immunol 2009; 27: 519-550.

67. Garib FY, Rizopulu AP, Kuchmiy AA, Garib VF. Inactivation of inflammasomes by pathogens regulates inflammation. Biochemistry (Mosc) 2016; 81: 1326-1339.

68. Muñoz-Carrillo JL, Muñoz-Escobedo JJ, Maldonado-Tapia CH, Chávez-Ruvalcaba F, Moreno-García MA. Resiniferatoxin lowers TNF- $\alpha, \mathrm{NO}$ and $\mathrm{PGE}_{2}$ in the intestinal phase and the parasite burden in the muscular phase of T. spiralis infection. Parasite Immunol 2017; 39: 1-14.

69. Muñoz-Carrillo JL, Contreras-Cordero JF, Muñoz-López JL, Maldonado-Tapia CH, Muñoz-Escobedo JJ, Moreno-García MA. Resiniferatoxin modulates the Th1 immune response and protects the host during intestinal nematode infection. Parasite Immunol 2017; 39: 1-16.

70. Sofronic-Milosavljevic LJ, Radovic I, Ilic N, Majstorovic I, Cvetkovic J, Gruden-Movsesijan A. Application of dendritic cells stimulated with Trichinella spiralis excretory-secretory antigens alleviates experimental autoimmune encephalomyelitis. Med Microbiol Immunol 2013; 202: 239-249.

71. Helmby H, Grencis RK. Contrasting roles for IL-10 in protective immunity to different life cycle stages of intestinal nematode parasites. Eur J Immunol 2003; 33: 2382-2390.

72. Gurish MF, Bryce PJ, Tao H, Kisselgof AB, Thornton EM, Miller HR, Friend DS, Oettgen HC. IgE enhances parasite clearance and regulates mast cell responses in mice infected with Trichinella spiralis. J Immunol 2004; 172: 1139-1145.

73. Wang LJ, Cao Y, Shi HN. Helminth infections and intestinal inflammation. World J Gastroenterol 2008; 14: 5125-5132.

74. Rogerio AP, Anibal FF. Role of Leukotrienes on Protozoan and Helminth Infections. Mediators Inflamm 2012; 2012: 595694.

75. Knight PA, Brown JK, Pemberton AD. Innate immune response mechanisms in the intestinal epithelium: potential roles for mast cells and goblet cells in the expulsion of adult Trichinella spiralis. Parasitology 2008; 135: 655-670.

76. Akiho H, Ihara E, Motomura Y, Nakamura K. Cytokine-induced alterations of gastrointestinal motility in gastrointestinal disorders. World J Gastrointest Pathophysiol 2011; 2: 72-81.

77. Rothenberg ME, Hogan SP. The eosinophil. Annual review of immunology. Annu Rev Immunol 2006; 24: 147-174.

78. Bruschi F, Korenaga M, Watanabe N. Eosinophils and Trichinella infection: toxic for the parasite and the host? Trends Parasitol 2008; 24: 462-467.

79. Vallance BA, Mathaei KI, Sanovic S, Young IG, Collins SM. Interleukin-5 deficient mice exhibit impaired host defence against challenge Trichinella spiralis infections. Parasite Immunol 2000; 22: 487-492.

80. Gottstein B, Pozio E, Nöckler K. Epidemiology, diagnosis, treatment, and control of Trichinellosis. Clin Microbiol Rev 2009; 22: 127-145.
81. Dupouy-Camet J, Kociecka W, Bruschi F, Bolas-Fernandez F, Pozio E. Opinion on the diagnosis and treatment of human trichinellosis. Expert Opin Pharmacother 2002; 3: 1117-1130.

82. Shimoni Z, Klein Z, Weiner P, MOccH, PFM. The use of prednisone in the treatment of trichinellosis. Isr Med Assoc J 2007; 9: 537-539.

83. Oakley RH, Cidlowski JA. Cellular processing of the glucocorticoid receptor gene and protein: new mechanisms for generating tissue-specific actions of glucocorticoids. J Biol Chem 2011; 286: 3177-3184.

84. Biddie SC, Conway-Campbell BL, Lightman SL. Dynamic regulation of glucocorticoid signaling in health and disease. Rheumatology 2012; 51: 403-412.

85. Nixon M, Upreti R, Andrew R. 5a-Reduced glucocorticoids: a story of natural selection. J Endocrinol 2012; 212: 111-127.

86. Serra HA, Roganovich JM, Rizzo LF. Glucocorticoides: paradigma de medicina traslacional. De lo molecular al uso clínico. Medicina 2012; 72: 158-170.

87. Charmandari E. Primary generalized glucocorticoid resistance and hypersensitivity. Horm Res Paediatr 2011; 76: 145-155.

88. Saklatvala Jeremy. Glucocorticoids: do we know how they work? Arthritis Res 2002; 4: 146-150.

89. De Iudicibus S, Franca R, Martelossi S, Ventura A, Decorti G. Molecular mechanism of glucocorticoid resistance in inflammatory bowel disease. World J Gastroenterol 2011; 17: 10951108.

90. Barnes PJ. Glucocorticosteroids: current and future directions. Br J Pharmacol 2011; 163: 29-43.

91. Barnes PJ. How corticosteroids control inflammation. Br J Pharmacol 2006; 148: 245-254.

92. Dostert A1, Heinzel T. Negative glucocorticoid receptor response elements and their role in glucocorticoid action. Curr Pharm Des 2004; 10: 2807-2816.

93. Belvisi MG. Regulation of inflammatory cell function by corticosteroids. Proc Am Thorac Soc 2004; 1: 207-214.

94. Wullaert A, Bonnet MC, Pasparakis M. NF-kB in the regulation of epithelial homeostasis and inflammation. Cell Res 2011; 21: 146-158.

95. Ray A, Prefontaine KE. Physical association and functional antagonism between the p65 subunit of transcription factor NFkappa B and the glucocorticoid receptor. Proc Natl Acad Sci USA 1994; 91: 752-756.

96. Scheinman RI, Gualberto A, Jewell CM, Cidlowski JA, Baldwin AS. Characterization of mechanisms involved in transrepression of NF-kappa B by activated glucocorticoid receptors. Mol Cell Biol 1995; 15: 943-953.

97. Flammer JR, Rogatsky I. Minireview: Glucocorticoids in autoimmunity: unexpected targets and mechanisms. Mol Endocrinol 2011; 25: 1075-1086.

98. Galon J, Franchimont D, Hiroi N, et al. Gene profiling reveals unknown enhancing and suppressive actions of glucocorticoids on immune cells. FASEB J 2002; 16: 61-71.

99. Ashwell JD, Lu FW, Vacchio MS. Glucocorticoids in T cell devel- 
opment and function. Annu Rev Immunol 2000; 18: 309-345.

100. Lasa M, Brook M, Saklatvala J, Clark AR. Dexamethasone destabilizes cyclooxygenase 2 mRNA by inhibiting mitogen-activated protein kinase p38. Mol Cell Biol 2001; 21: 771-780.

101. Lamas AM, Leon OG, Schleimer RP. Glucocorticoids inhibit eosinophil responses to granulocyte-macrophage colony-stimulating factor. J Immunol 1991; 147: 254-259.

102. Arai Y, Nakamura Y, Inoue F, Yamamoto K, Saito K, Furusawa S.. Glucocorticoid-induced apoptotic pathways in eosinophils: comparison with glucocorticoid-sensitive leukemia cells. Int J Hematol 2000; 71: 340-349.

103. Bozic F, Jasarevic A, Marinculic A, Durakovic E, Kozaric Z. Dexamethasone as a modulator of jejunal goblet cells hyperplasia during Trichinella spiralis gut infection of mice. Helminthologia 2000; 37: 3-8.

104. Alvarado RM, Meza LE, García ME, Saldívar S, Moreno GA. Hormonal effect on the parasite load in the infection by T. spiralis of a murine experimental model. Trichinellosis. 9th International Conference on Trichinellosis (ICT9). Edit. Ortega P., Wakelin 1996; 107-114.

105. Piekarska J, Szczypka M, Michalski A, Obminska-Mrukowicz B, Gorczykowski M. The effect of immunomodulating drugs on the percentage of apoptotic and necrotic lymphocytes in inflammatory infiltrations in the muscle tissue of mice infected with Trichinella spiralis. Pol J Vet Sci 2010; 13: 233-240.

106. Salazar H, Jara-Oseguera A, Rosenbaum T. El canal TRPV1 como diana para tratar el dolor. Rev Neurol 2009; 48: 357-364.

107. Pal M, Angaru S, Kodimuthali A, Dhingra N. Vanilloid receptor antagonists: emerging class of novel anti-inflammatory agents for pain management. Curr Pharm Des 2009; 15: 1008-1026.

108. Nilius B, Szallasi A. Transient receptor potential channels as drug targets: from the science of basic research to the art of medicine. Pharmacol Rev 2014; 66: 676-814.

109. Carnevale V, Rohacs T. TRPV1: a target for rational drug design. Pharmaceuticals (Basel) 2016; 9: 52.

110. Lee YH, Im SA, Kim JW, Lee CK. Vanilloid receptor 1 agonists, capsaicin and resiniferatoxin, enhance MHC class I-restricted viral antigen presentation in virus-infected dendritic cells. Immune Netw 2016; 16: 233-241.

111. Singh S, Natarajan K, Aggarwal BB. Capsaicin (8-methyl-Nvanillyl-6-nonenamide) is a potent inhibitor of nuclear transcription factor-kappa B activation by diverse agents. J Immunol 1996; 157: 4412-4420.

112. Chen CW, Lee ST, Wu WT, Fu WM, Ho FM, Lin WW. Signal transduction for inhibition of inducible nitric oxide synthase and cyclooxygenase-2 induction by capsaicin and related analogs in macrophages. Br J Pharmacol 2003; 140: 1077-1087.

113. Ueda K, Tsuji F, Hirata T. Preventive effect of TRPV1 agonists capsaicin and resiniferatoxin on ischemia/reperfusion-induced renal injury in rats. J Cardiovasc Pharmacol 2008; 51: 513-520.

114. Gutiérrez-Coronado Oscar, Muñoz-Carrillo JL, Miranda-Beltrán ML, Pérez-Vega MI, Soria-Fregozo C, Villalobos-Gutiérrez PT. Evaluación de la actividad antiinflamatoria de resiniferatoxina en un modelo murino de inflamación inducido por Lipopolicacárido. Rev. Latinoamer. Quím 2012; 39: 287.

115. Levi-Schaffer F, Temkin V, Malamud V, Feld S, Zilberman Y. Mast Cells Enhance Eosinophil Survival In Vitro: Role of TNF- $\alpha$ and Granulocyte-Macrophage Colony-Stimulating. Factor J Immunol 1998; 160: 5554-5562.

116. Uings I, Puxeddu I, Temkin V, Smith SJ, Fattah D, Ray KP, LeviSchaffer F. Effects of dexamethasone on TNF-alpha-induced release of cytokines from purified human blood eosinophils. Clin Mol Allergy 2005; 3: 1-5.

117. Hebestreit H, Yousefi S, Balatti I, Weber M, Crameri R, Simon D, Hartung K, Schapowal A, Blaser K, Simon HU. Expression and function of the Fas receptor on human blood and tissue eosinophils. Eur J Immunol 1996; 26: 1775-1780.

118. Létuvé S, Druilhe A, Grandsaigne M, Aubier M, Pretolani M. Involvement of caspases and of mitochondria in Fas ligationinduced eosinophil apoptosis: modulation by interleukin-5 and interferon-gamma. J Leukoc Biol 2001; 70: 767-775

119. Hebestreit H, Dibbert B, Balatti I, Braun D, Schapowal A, Blaser K, Simon HU. Disruption of Fas Receptor Signaling by Nitric Oxide in Eosinophils. J Exp Med 1998; 187: 415-425.

120. Fabre V, Beiting DP, Bliss SK, Gebreselassie NG, Gagliardo LF, Lee NA, Lee JJ, Appleton JA. Eosinophil deficiency compromises parasite survival in chronic nematode infection. J Immunol 2009; 182: 1577-1583.

121. Huang L, Gebreselassie NG, Gagliardo LF, Ruyechan MC, Lee NA, Lee JJ, Appleton JA. Eosinophil-derived IL-10 supports chronic nematode infection. J Immunol 2014; 193: 4178-4187.

122. Huang L, Gebreselassie NG, Gagliardo LF, Ruyechan MC, Luber KL, Lee NA, Lee JJ, Appleton JA. Eosinophils mediate protective immunity against secondary nematode infection. J Immunol 2015; 194: 283-290.

123. Huang L, Beiting DP, Gebreselassie NG, Gagliardo LF, Ruyechan MC, Lee NA, Lee JJ, Appleton JA. Eosinophils and IL-4 support nematode growth coincident with an innate response to tissue injury. PLoS Pathog 2015; 11: 1-17. 
